\title{
Foreign Exchange Rates Are Predictable!
}

\author{
Hui Guo
}

M odern economic theory of foreign exchange rates stipulates that the Deutsche mark/U.S. dollar rate, for example, is equal to discounted future fundamentals-e.g., aggregate income, interest rates, and monetary aggregates - in both the United States and Germany. A substantial portion of the variation in these fundamental macroeconomic variables is predictable across time; therefore, fundamentals should provide important information about future movements in exchange rates. In an influential paper, Meese and Rogoff (1983), however, find that a simple random walk model, in which the forecasted value is the most recent realization, outperforms various forecasting models, including those using economic fundamentals as predictors. ${ }^{1}$

Meese and Rogoff's result has inspired numerous empirical investigations of exchange rate predictability, and their conclusion has proven to be strikingly robust after 20 years of fresh data and intensive academic research. In light of seemingly compelling evidence, some recent authors argue that exchange rates are indeed unpredictable-possibly because some shocks have a permanent effect on economic fundamentals. In particular, if people discount the future very little relative to the present, then exchange rates could follow a process close to a random walk.

Other economists, however, argue that exchange rates are predictable and that existing empirical studies suffer from various misspecifications. For example, some crucial fundamental determinants of exchange rates may have been omitted. Also, many macroeconomic variables are subject to periodic revisions; therefore, the current vintage data, which have been commonly used available to investors at the time of forecast. To address these issues, Guo and Savickas (2005) propose using financial variables, which are broad measures of business conditions and never revised, to predict exchange rates. ${ }^{2}$

Guo and Savickas find that a measure of U.S. aggregate idiosyncratic volatility (IV) is a strong predictor of the exchange rates of the U.S. dollar against major foreign currencies, especially at relatively long horizons. An idiosyncratic shock to a stock is the part of the stock return that is not explained by asset pricing models. To measure IV, Guo and Savickas first estimate idiosyncratic shocks to all (U.S.) common stocks included in the CRSP (Center for Research in Security Prices) database; they then aggregate the realized variance of idiosyncratic shocks across stocks using the share of market capitalization as the weight.

The accompanying chart plots IV from the last quarter of each year (in natural logarithms, solid line) along with one-year-

ahead changes (December 31 to December 31 of the following year, dashed line) in the Deutsche mark/U.S. dollar rate over the period 1973 to 1998 and the Euro/U.S. dollar rate over the period 1999 to 2003 . The chart reveals a strong positive relation between IV and changes in the price of the U.S. dollar over the next year. For example, recent depreciation of the U.S. dollar was preceded by a sharp decline in IV in the year 2001. Overall, IV accounts for more than 30 percent of the variation of the Deutsche mark/ U.S. dollar rate; IV also outperforms the random walk model in out-of-sample forecasting.

The forecasting power of IV is consistent with economic theory. In particular, many early authors have argued that IV is a proxy for the dispersion of shocks across different sectors; and a high level of dispersion induces costly sectoral resource reallocation, which reduces output and employment. Indeed, Guo and Savickas show that IV is a strong predictor of GDP growth, fixed private business investment, and unemployment rates. Moreover, they find that a measure of aggregate IV constructed using German stock price data is also positively related to future dollar prices of the Deutsche mark. Therefore, although we cannot completely rule out the possibility of data mining, the forecasting power of IV appears to provide support for the conjecture that economic fundamentals are important determinants of foreign exchange rates.

${ }^{1}$ Meese, Richard A. and Rogoff, Kenneth. "Empirical Exchange Rate Models of the Seventies: Do They Fit Out of Sample?" Journal of International Economics, February 1983, 14(1), pp. 3-24.

\section{Log IV vs. Changes in Deutsche Mark (1973-98) and Euro Rates (1999-2003) One Year Forward}

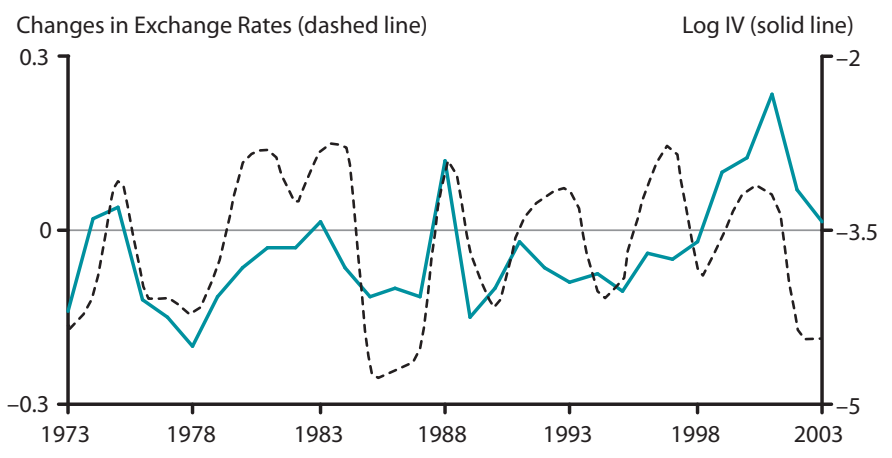

